\title{
Clinician and carer moral concerns when caring for children who tube-feed
}

Journal of Child Health Care 2021, Vol. 0(0) I-15

(C) The Author(s) 2021 Article reuse guidelines: sagepub.com/journals-permissions DOI: $|0.1| 77 /|36749352| 1052842$ journals.sagepub.com/home/chc

(\$)SAGE

\author{
Ann Dadich'荢, Kaitlyn Hockey', Cathy \\ Kaplun $^{2}$, Catharine Fleming ${ }^{3}$, Nick \\ Hopwood $^{4}$, Khadeejah Moraby ${ }^{5}$ and Chris \\ Elliot $^{6}$
}

\begin{abstract}
Child healthcare can be vexed by moral concerns - this extends to the care of children who tubefeed. Children who tube-feed often receive care from family members and clinicians of various disciplines. Each brings expertise, experiences, values, and views to a situation, prioritising the child's needs while attending to those they deem important in potentially disparate ways. Their understanding of a situation is shaped by beliefs, feelings, and perceptions. How then are key decisions made about the care of a child who tube-feeds? This article explores clinicians' and carers' moral concerns when caring for children who tube-feed. Interviews with clinicians $(n=9)$ and carers $(n=9)$ clarified three findings: first, there are often disparate beliefs about the need for tubefeeding; second, tube-feeding can evoke strong emotions; and third, it can be difficult to normalise tube-feeding. This article demonstrates how challenges can emerge when relationships between clinicians and carers diverge. Furthermore, it establishes how an ethic of care can bring different interests together to bolster the relationships required to optimise feeding care and promote health outcomes among children who tube-feed and their carers. This requires improved dialogue between and among clinicians and carers to create shared understandings of what is, what should be, and how to benefit children who tube-feed.
\end{abstract}

\footnotetext{
' School of Business, Western Sydney University, Penrith South, NSW, Australia

${ }^{2}$ School of Nursing and Midwifery, Western Sydney University, Penrith South, NSW, Australia

${ }^{3}$ School of Science and Health, Western Sydney University, Penrith South, NSW, Australia

${ }^{4}$ Faculty of Arts and Social Science, University of Technology Sydney, Sydney, NSW, Australia

${ }^{5}$ SA Health, Central Early Childhood and Families Service, Women's and Children's Health Network, Adelaide, SA, Australia

${ }^{6}$ Department of Paediatrics, Saint George Private Hospital, Kogarah, NSW, Australia
}

Corresponding author:

Ann Dadich, School of Business, Western Sydney University, Locked Bag 1797, Penrith South, NSW 275I, Australia.

Email: A.Dadich@westernsydney.edu.au 


\section{Keywords}

Child health, enteral nutrition, feeding and eating disorders, morals, qualitative research

\section{Introduction}

From an ethic of care perspective (Gilligan, 1982), this article frames moral issues as relationship matters in child healthcare - this is demonstrated with reference to the care of children with feeding difficulties, particularly those who tube-feed. Caring for children who tube-feed can present several issues for clinicians and carers, particularly when their relationship diverges (Craig and Higgs, 2012; Freitag, 2018). As this article demonstrates, this can give rise to different beliefs about tubefeeding, strong feelings evoked by tube-feeding, and the difficult actions of normalising tubefeeding.

This article focuses on the care of children with feeding difficulties because it typifies complexities that surround child healthcare. Feeding difficulties are common with '20-50\% of typically developing children... and 40-70\% of children born preterm... experience[ing]... feeding problem(s)' (Zimmerman and Rosner, 2018: 1). This prevalence is partly due to its breadth, encompassing medical, behavioural, and/or psychosocial causes (Goday et al., 2019). Regardless of cause, feeding difficulties among children can compromise child wellbeing; generate carer anxiety and family strain (Silverman et al., 2021); and warrant greater access to (mental) health services, adding to healthcare costs (Sharp et al., 2018).

Notwithstanding a few guidelines (NSW Health, 2016; Richards, 2017), there are no (inter) national clinical guidelines or models of care to guide quality feeding care - this is particularly the case for children who tube-feed. There is limited clinical information to indicate which clinicians should be involved in tube-feeding and how; there is limited governance advice on how clinicians and carers might collaborate to optimise health outcomes; and there is limited ethical guidance on how to manage different priorities or interests. Hence, children who tube-feed and/or their carers often receive 'inconsistent' (Tang et al., 2018) care. This follows the variable availability of appropriate training; competent support teams; resources and care standards (Gramlich et al., 2018).

Variable tube-feeding care can give rise to moral concerns, or apprehensions about another's well-being (Dungan et al., 2019). While food represents a basic human need, it is also a medium that conveys care (Almqvist-Tangen et al., 2017). However, when a child cannot consume food, orally, and requires tube-feeding, moral concerns can emerge (Mahant et al., 2018; Serjeant and Tighe, 2021). Consider concerns about: if and when to tube-feed; the discomfort sometimes associated with tube-feeding; how to manage tube-feeding; the limited opportunity for children who tube-feed to exercise personal agency; the stigma often associated with tube-feeding for children, carers, and families, and the expected duration of tube-feeding. Craig and colleagues (2003: 183) alluded to many of these. They found 'parental accounts of oral and tube-feeding were... contradictory and ambivalent... informed by normative constructions of good parenting and 'normal' child development' (183-186). They concluded that a 'biomedical emphasis on health and weight-gains might fail to reflect parental concerns about tube and oral feeding'. These conundrums represent complex moral judgements, as they concern what matters to children and those who care for them. Yet, limited research clarifies how tube-feeding occurs or should occur. This study addresses this.

This study illuminates the dilemmas that can emerge when clinician and carer relationships are compromised. This is achieved by analysing interviews with clinicians and carers who supported children who tube-feed. Given the findings, this article argues that relationships underpin individual 
autonomy. Specifically, by adopting an ethic of care, clinician and carer concerns can helpfully coalesce in shared decision-making that benefit their relationships, as well as child and carer health. This approach serves to avert the potential clash and impasse of clinical autonomy versus carer and patient autonomy.

\section{Moral concerns in child health care}

Framed within an ethic of care, moral concerns arise when the relationship between those who provide and receive care is compromised (Conradi, 2018). For example, particular individuals and/ or agendas dominate or are overshadowed, and relationships are not prized. In essence, moral concerns emerge when individuals and collectives fail to pay attention; and/or are absent or fail to respond with respect and integrity (Gilligan, 2014). They can manifest in different ways. For instance, they can involve differences in beliefs that are not appreciated (Philosophy Lander, n.d.); 'special kind[s] of feeling[s] [like]... satisfaction, shame or guilt' (para. 7-9); and/or actions that affect others, like ignoring them.

Unlike other approaches to understand moral concerns (Beauchamp and Childress, 2001; Mandal et al., 2016), an ethic of care 'recast[s] the conversation about self and morality as a conversation about... relationships' (Gilligan, 2014: 89). Undergirded by 'a psychological logic of relationships', rather than a 'formal logic of fairness' (Gilligan, 1982: 73), it recognises the importance of 'trust and responsibility, protection of individuality, the context in which the relationship takes place and the quality of the relationship' (De Panfilis et al., 2019: 3). Furthermore, it recognises listening as a way to fortify trust, strengthen relationships and foster empathy.

While recognising its critiques - for instance, its potential to reduce the relationship of care to particular features that reinforce gendered stereotypes (Ferguson, 1991; Tong and Williams, 2018) - an ethic of care is particularly relevant to child healthcare (Moreton, 2019). Thislargely follows its three foundational theoretical commitments (Held, 2006). First, 'persons are understood to have varying degrees of dependence and interdependence' (Mackay, 2020: 78), which is often the case among children with complex health issues, their carers, and clinicians. Second, 'anyone who is particularly vulnerable to one's choices and their outcomes deserves extraconsideration when making decisions' (Mackay, 2020: 78), reflecting the vulnerabilities often experienced by children with complex health issues, carers, and clinicians (Houtzager et al., 2015). And third, as suggested by research on child healthcare (Camp-Spivey et al., 2021), context matters - that is, 'the contextual details of situations must be part of the decision-making... to safeguard and promote the actual interests of those concerned' (Mackay, 2020: 78).

For three key reasons, child healthcare can be vexed by moral concerns. First, child healthcare typically requires a multidisciplinary approach (Brenner et al., 2018). Professionals of different disciplines work with the child and carer towards a shared goal, with each team member (including the child and carer) bringing different expertise, experiences, and views to a situation. Although they might each prioritise child wellbeing, they are each likely to attend to factors or perceptions they deem to be important and do so in disparate ways (Mahant et al., 2018). This is because their understanding of a particular situation is shaped by their worldview, encompassing values, experiences, knowledge, and discourse. Second, the health of a child can elicit strong feelings (Almqvist-Tangen et al., 2017). For instance, parental concern can ignite protectiveness (DuPen et al., 2016). Furthermore, a clinician's duty of care can spur a strong commitment to a child's wellbeing and give rise to burnout (Blazin et al., 2021). Third, the ways in which child healthcare is 
enacted directly affect the child and their carer. These reasons are aptly demonstrated in the context of paediatric feeding disorders, particularly among children who tube-feed.

\section{Paediatric feeding disorders}

Although feeding difficulties can be part of normal child development, a feeding disorder is typically indicated when the following occur for at least two weeks: impaired oral intake, which is not age-appropriate; medical, nutritional, or psychosocial dysfunction; or limited feeding skills (Goday et al., 2019). Treatment for feeding disorders aims to ensure a child remains well-nourished and receives adequate energy and nutrient intake for growth and neurocognitive development (Yang, 2017). Some individuals who cannot maintain adequate nutrition, orally, require enteral nutrition or tube-feeding (Pearce and Duncan, 2002). This might involve: a nasogastric tube (inserted into the nose and through to the stomach); an orogastric tube (inserted into the mouth andthrough to the stomach); or a percutaneous endoscopic gastrostomy tube (surgically inserted through the anterior abdomen into the stomach) (Richards, 2017).

Although tube-feeding can improve energy and nutritional intake, it can also incite challenges (Serjeant and Tighe, 2021). For instance, clinicians and carers must negotiate decisions about: if and when to introduce tube-feeding; the type of tube-feeding that is likely to be beneficial for the child; the associated physiological, developmental, or psychological consequences; who will tube-feed the child at home or school; and when the tube might be removed. These decisions are not solely determined by clinical needs (Craig et al., 2003) - they are also determined by clinician and carer expertise; their beliefs about what the child needs and prefers; and their capacity to work together towards the child's wellbeing.

Decisions regarding tube-feeding are often made at difficult times (Harris et al., 2018). For instance, carers are likely be anxious and/or frustrated by their child's limited food intake and what this might suggest about their caring skills; while clinicians are likely to have limited resources, including time, to negotiate decisions in ways that helpfully coalesce their clinical knowledge with the carers' and child's lived experiences (Freitag, 2018; Hopwood et al., 2020).

These challenges can compromise decision-making. This is largely because it can take time and energy to carefully deliberate options and the associated implications. This was suggested by research that pointed to three key sources of decisional conflict (Adams and Elias, 2014) - namely, context, that is, 'the unique circumstances of each child and family'; values, that is, the 'struggle between the value and meaning (for parents) of oral feeding and potential losses associated with... tube-feeding'; and the processes of care, where there is 'inadequate information-sharing and support for families' (Mahant et al., 2018: 10). And when individuals are anxious or resource-poor, de- cisions can become biased and flawed (Park et al., 2016). Fraught decision-making can also give rise to moral concerns.

Moral concerns can influence feeding care (Craig and Scambler, 2006). They can have a bearing on: the decision about tube-insertion; how tube-feeding is explained to the child, their family, and friends; how tube-feeding should be managed; the social situations the child should be part of, or protected from; and when a tube should be removed (Craig and Higgs, 2012; Hopwood et al., 2020). Yet, there is a limited understanding of how decisions are made about the care of a child who is tubefed.

This represents an important line of inquiry for two key reasons. First, moral concerns matter, particularly for children with complex health issues, like those who tube-feed. Moral concerns can shape healthcare and thus child health - particularly in the absence of guidelines to manage these 
concerns. Second, relatively little is known about feeding difficulties among children, how to manage them, the factors that shape feeding care, like moral concerns, and how to enhance feeding care. This article addresses this gap.

\section{Aim}

To extend understandings of moral concerns in the context of child healthcare (Carnevale and Manjavidze, 2016). This is achieved by using tube-feeding as a microcosm of care.

\section{Method}

Following clearance from the relevant human research ethics committee (approval number: H13794), clinicians involved in caring for children who tube-feed and carers of children who tubefeed were invited to participate in a semi-structured interview. Clinicians were primarily recruited via purposeful sampling (Harsh, 2011). Clinicians known to be aged 18 years or older, residing in Australia, and having spent most of their working week engaged in feeding care for children aged under 18 years were invited to participate via email. Carers were primarily recruited via social media platforms - namely, Facebook and Twitter - and webpages managed by relevant organisations (e.g., SUCCEED Study Group, ausEE Inc., SPHERE In the Know). Carers were invited to contact the researchers if they were aged 18 years or older; resided in Australia; and cared for a child aged under 18 years who tube-fed within the last 5 years - this helped to optimise the currency of the findings. Participant recruitment of both cohorts continued until data saturation (Braun and Clarke, 2021).

Two interview schedules were devised for the clinicians and carers. The schedule for the clinicians pertained to how they became interested in feeding difficulties and/or tube-feeding, particularly among children; what they have found useful when supporting children who tube-feed and/or their carers, why, and the associated implications; the factors and/or circumstances that informed their clinical decisions; the knowledges that influenced, and were influenced by their practices; what they wish they would have known about feeding care, earlier in life; and what all clinicians should know about feeding care. Given the focus of this article, only findings pertaining to moral concerns are presented.

The schedule for the carers pertained to the lived experiences of tube-feeding (e.g., how they managed tube-feeding and family mealtimes, why, and the associated implications); what informed their decisions, particularly during the initial and later phases of tube-feeding; what helped or hindered feeding care (e.g., clinician practices, access to particular services); the priorities and considerations that mattered to them and why; what they wish they had known about feeding care, earlier in life; and what all carers should know about feeding care.

Following informed consent, the interviews were conducted via web-conference for approximately one hour. The interviews were digitally-recorded and transcribed for thematic analysis (Braun et al., 2018). One researcher (re)read and reviewed the transcripts to ascertain patterns within the dataset and construct broad (or higher order) themes that reflected participant experiences and perceptions. To clarify their moral concerns, particular attention was attended to beliefs, feelings and/or actions that promoted or demoted relationships and dialogue between different voices. This process was aided by Quirkos version 2.3.1 - computer-assisted qualitative data analysis software. To optimise veracity, two other researchers analysed three randomly selected transcripts. The three 
researchers conferred about their respective themes and reconciled differences. When presenting the findings, pseudonyms are used to protect participant confidentiality.

\section{Findings}

Participants included nine clinicians and nine carers (see Table 1). The clinicians' median years of experience in child healthcare was nine (quartile-2: 9 years), while the carers had a median of three years of experience in caring for a child with a feeding disorder (quartile-2: 3 years).

The participants spoke of three key concerns when caring for children who tube-feed. These included disparate beliefs about the need for tube-feeding; the strong feelings that tube-feeding

Table 1. Participant demographic details and attributes.

\begin{tabular}{|c|c|c|}
\hline Cohort & Characteristic & $n(\%)$ \\
\hline \multirow[t]{13}{*}{ Clinicians $(n=9)$} & Age (years) & \\
\hline & Median & 32 \\
\hline & IQR & 15.5 \\
\hline & Gender (female) & $8(88.9)$ \\
\hline & Geographical location & \\
\hline & Queensland & $9(100.0)$ \\
\hline & Discipline & \\
\hline & Dietetics & 7 (77.8) \\
\hline & Speech pathology & $2(22.2)$ \\
\hline & Experience in child health care (years) & \\
\hline & Median & 9 \\
\hline & IQR & 12.5 \\
\hline & Employed in a tertiary health service & 3 \\
\hline \multirow[t]{21}{*}{ Carers $(n=9)$} & Age (years) & \\
\hline & Median & 38 \\
\hline & IQR & 17 \\
\hline & Gender (female) & $8(88.9)$ \\
\hline & Geographical location & \\
\hline & New South Wales & $2(22.2)$ \\
\hline & Victoria & $2(22.2)$ \\
\hline & Queensland & $2(22.2)$ \\
\hline & Unspecified & $3(33.3)$ \\
\hline & Employment status & \\
\hline & Full-time employed & $3(33.3)$ \\
\hline & Part-time employed & $3(33.3)$ \\
\hline & Unemployed & $2(22.2)$ \\
\hline & Retired & I (II.I) \\
\hline & Experience in supporting children with feeding & \\
\hline & Median & 1.5 \\
\hline & IQR & 3 \\
\hline & Age of child with a feeding disorder (years) & \\
\hline & Median & 3 \\
\hline & IQR & 1.5 \\
\hline & Gender of child with a feeding disorder (male) & $6(66.7)$ \\
\hline
\end{tabular}


evoked; and the disparate ways to normalise tube-feeding, which affected the child who tube-fed and other family members. As demonstrated in the following sections, these concerns were largely driven by an underlying moral concern - namely, care that promotes relationships that optimise the shared endeavour of tube-feeding care.

\title{
Beliefs about tube-feeding
}

The decision to commence tube-feeding was often vexed by disparate beliefs about whether it was warranted and the expected duration of tube-feeding. This was partly because of conflicting views about the causes and severity of the child's feeding difficulty. For instance, some family members assumed the child just needed to eat, and tube-feeding was unwarranted; while some clinicians approached each feeding difficulty in the same way, without considering the child or carer's needs and preferences:

\begin{abstract}
'The older generation can't get their heads around why he is actually not eating, and they seem to think if you just didn't tube-feed, then kids miraculously start eating... people just can't grasp why a child - when it's got no other medical problems - won't eat' (Amelia-carer).

'You constantly come across specialists who are by-the-book and don't listen. They treat all kids the same. They don't look at them as individuals on their individual needs and capabilities' (Anna-carer).
\end{abstract}

These tensions were exacerbated by the absence of universally accepted tube-feeding guidelines to inform how clinicians assess severity and manage feeding disorders. This is because the timing of tube-insertion, tube-weaning, and/or progression to a long-term feeding apparatus was often contentious. Consider the decision between prophylactic tube-feeding to prevent a failure-to-thrive or inserting a tube only after significant weight loss. Given that tube-feeding can be associated with considerable side-effects (Krom et al., 2019), the decision to tube-feed was not always simple:

'The parents always... want what is best for their child... we... initially get a ... bit of resistance with tubes. But... by the time we're questioning whether the child needs a tube... the parents are at their witsend and they just want their child to be hydrated and... have nutrition. So, they're generally really open to it. But they can find it quite confronting and overwhelming... learning about it' (Lucy-clinician).

'I do have a few families I'm battling with, where their point of view is just never correct... it's a case of just kind of stampeding them with information, like - "You need to start listening or your child is not going to start thriving"' (Elizabeth-clinician).

Some carers were unable to make an informed decision about tube-feeding because of limited access to consistent information, and the despair they experienced to have their child's health issues addressed. Given their sense of hopelessness, some believed they had little choice and felt obliged to follow medical advice:

\footnotetext{
'We didn't really have any education... We just said yes because... we were desperate... we have been left in the dark... We've been... left to figure out quite a bit of it ourselves, because... we're seeing these different specialists... not one team... [The paediatrician] was telling us one thing, then the hospital nutritionist was telling us something different' (Amelia-carer).
} 
'Different nursing staff might give different information about how to care for the tube, or between nursing staff and doctors... The company... with the ongoing support at home will give them different information as well' (Lucy-clinician).

To manage some of the divergent beliefs about tube-feeding, some participants highlighted the importance of a team approach. When multidisciplinary clinicians can regularly confer with a carer about a child's feeding difficulties, there is greater opportunity to develop a shared understanding of the options to support the child, as well as the pros and cons of each:

'It's better when there's a whole-team approach... Having a speech therapist and diet together. Ideally, you'd also have social work. It really helps because... families get one message and they come to one appointment - they're not getting conflicting information or getting confused' (Danielaclinician).

Divergent beliefs about tube-feeding and their influence on feeding care highlight the need for an ethic of care. Of key moral significance are the interdependent relationships between clinicians, carers, and children who tube-feed, yet those involved might have different beliefs and associated priorities. So, an underlying moral concern must be to effectively nurture these relationships while making decisions amid contrasting, and potentially opposing, views.

\section{Feelings evoked by tube-feeding}

Many participants were cognisant that tube-feeding often evoked strong emotions. The tube-feeding paraphernalia and the act of tube-feeding were visible indications of an aberration or anomaly. This was particularly the case for children with a nasogastric or an orogastric tube, which was visible to others:

'[the tube] is visual. It's a constant reminder for families and for other people in the public about what's wrong with their child, and I think there's a lot of negative connotations that go with that' (Justineclinician).

Given that difference can be disconcerting, some participants were concerned by the psychosocial effects of tube-feeding on the child and family. Some, particularly carers, spoke of the isolated nature of tube-feeding. They sometimes felt alone, unable to connect with others who did not understand the life of tube-feeding:

'You always got people staring at you, wondering what was going on. Most of the time, it was just curiosity. Kids will most likely to come up and ask questions' (Anna-carer).

'You don't really have anyone to talk to' (Amelia-carer).

Furthermore, repeated tube-insertions were often disturbing for the child and carer. The experience could be emotionally taxing, compromising the relationship between carer and child:

'Towards the end before he had the [gastrostomy tube] ... it became quite an event for him. So, I didn't want him to relate the tube to me... It can be quite risky. They can aspirate if you don't get in the right spot. I just don't want that responsibility' (Fiona-carer). 
The feelings associated tube-feeding were sometimes overwhelming. Some participants noted that when carers are beleaguered with a lot of new information, some of which might be contradictory, they might feel paralysed, unable to make sense of and manage tube-feeding care:

'For some parents, it's hard for them to understand if we're being over-the-top with it... sometimes I find even just setting one goal... 'What's the most important at the moment? There might be five things that we need to work on. But, at the moment, if one thing from me is all you can manage because you've got five other things that someone else has told you to do [then so be it]' (Penny-clinician).

The feelings evoked by tube-feeding reinforce the importance of an ethic of care. They speak directly to the symbiotic relationship between clinicians, carers, and children who tube-feed. They also point to the careful deliberation required when deciding how to manage tube-feeding, which must consider how different situations influence feeding care, especially those beyond a clinical setting.

\section{Actions to normalise tube-feeding}

According to the participants, tube-feeding can be disruptive. Carers reported that much of the family's routine was adapted to suit their child's complex care needs. For instance, venturing beyond the home to purchase groceries, visit family, or meet friends depended on their ability to organise the tube, tape, formula, sterile water, and pump, among other items. Without organisational skills, tubefeeding 'could chain you to your house' (Amelia-carer):

\section{'We would take him out for picnics... and take... a little picnic basket... you just have to be organized' (Amelia-carer).}

Tube-feeding was time-consuming, particularly when gravity feeding was used, whereby 'formula flows... from [the]... bag and into [the]... tube by... gravity' (Memorial Sloan Kettering Cancer Center, 2020: para. 2). The relatively unpredictable nature of intermittent tube-feeding often required the family to separate main meals from the child's tube-feeding requirements. Although many participants acknowledged the importance of shared mealtimes, they conceded it was often difficult to combine the two. As such, the divergence between family mealtimes and the child's mealtimes gave rise to tension:

'I think we need to think about how we can normalise our feeding plans to mimic that of a normal feeding baby or child... breakfast, lunch, and dinner' (Justine-clinician).

'The biggest thing is trying to make sure the child still enjoys mealtimes... trying to make them fit into the normal mealtime pattern as much as possible, while they've got the tube' (Diana-clinician).

It was particularly difficult to normalise tube-feeding when only one carer had been trained in tube-feeding. This placed considerable responsibility on the carer who sometimes cared for other children. Although additional carers could be trained, they were sometimes apprehensive about assuming this role:

'For a different child, siblings would be able to put her in her highchair... But because [my child] is connected to her pump at mealtimes, that's something that falls onto me. It just changes those 
dynamics... We can't just say, "Everyone, go and sit at the table, it's dinner time"... Everybody has to wait for us to get [my child] sorted" (Katherine-carer).

'I think [my parents] were obviously pretty nervous [about tube-feeding]' (Amelia-carer).

Actions to normalise tube-feeding indicate the significance of an ethic of care grounded in relationships between those involved. This signals the need for clinicians to recognise the importance of normalcy for carers and that this might manifest in different ways, depending on what matters in specific families. Embedding tube-feeding in 'normal' routines, especially around mealtimes, is crucial to many in terms of making meals a site of togetherness and enjoyment.

\section{Discussion}

This article demonstrates that clinicians and carers experience concerns when caring for children who tube-feed. This was indicated by an analysis of interviews with nine clinicians and nine carers who cared for children who tube-fed. The analysis highlighted three findings. First, there are often disparate beliefs about the need for tube-feeding, which were not always appreciated. Second, tubefeeding can evoke strong emotions, including stigma and isolation. Third, it can be difficult to normalise tube-feeding and balance family routines with tube-feeding requirements. These findings demonstrate some of the beliefs, feelings, and actions that emerge when relationships between clinicians and carers are compromised.

The clinicians and carers sometimes struggled to find common ground to support the child who tube-fed. This occurred when particular beliefs, feelings, or actions were eclipsed, and relationships were not respected (Gilligan, 2014). This was largely because clinicians and carers bring different expertise, experiences, and views to a situation. Although they might each prioritise the child's needs, they can attend to those they deem important and do so in divergent ways (Adams and Elias, 2014; Mahant et al., 2011, 2018). How then are key decisions made about the care of a child who is tube-fed?

By addressing this line of inquiry, this article highlights the beliefs, feelings and actions of clinicians, carers, and extended family members that arise when relationships and dialogue between 'different voice[s]' (Gilligan, 1982) are demoted. This in turn can shape the healthcare received by children who tube-feed.

These findings stress the importance of an ethic of care (Gilligan, 1982). Specifically, they demonstrate the interdependence of clinicians, carers, and children who tube-feed; the "extra consideration [required] when making decisions' (Mackay, 2020: 78) about feeding care; and the influential role of context. By awarding primacy to relationships, an ethic of care can bring clinician and carer concerns together in shared decision-making to strengthen their relationship, as well as the health of the child and their carer.

\section{Study limitations}

Five methodological limitations warrant mention. First, because participants were self-selected, there is no claim they constitute a representative sample of clinicians or carers who have supported children who tube-feed. Second, given the study only involved 18 participants, there is no claim the findings are generalisable to a broader group of people or situations. Third, given the research 
design, it is not possible to isolate variables - like participants' demographic characteristics - that contributed to these findings. Fourth, reliance on cross-sectional qualitative material limits the lifespan of the identified findings, particularly because of the potential for social desirability bias (Sanzone et al., 2013). Fifth, children were not represented in the study - as such, children's experiences with, and perceptions of the concerns presented in this article are yet to be examined.

\section{Implications for practice and research}

The findings have implications for clinicians and carers. Specifically, they speak to the moral undertones of tube-feeding, whereby beliefs, particular feelings, and actions that affect others, come to the fore (Philosophy Lander, n.d.). Furthermore, as this article has demonstrated, the intersection of different concerns can shape how clinicians, carers, and children who tube-feed work together towards a shared goal. As one participant noted, 'a whole-team approach' can ensure that all team members are 'on the same page'.

These findings therefore suggest a need for improved dialogue between clinicians and carers, rather than simply more dialogue. They require regular opportunities to engage in open and candid communication; exchange knowledge and expertise; consider and critique moral concerns; and create shared understandings of how to support children who tube-feed. This might involve informal (e.g., peer support groups, online fora) and formal arrangements (e.g., research projects, codesigned interventions, resources, and guidelines).

The point here is not to dictate what people do - but to encourage clinicians and carers to partner. That is, to pay attention - particularly to the intersections of their beliefs, emotions, and actions; to be present and to respond with respect and integrity (Gilligan, 2014). In effect, the point is to promote dialogue between 'different voice[s]' (Gilligan, 1982), understanding, concordance, and relationships to optimise child and carer health.

Using tube-feeding guidelines as an example - given the lack of (inter)national guidelines or models - this might involve ensuring recognition of people's 'varying degrees of dependence and interdependence'; 'extra consideration when making decisions'; and flexibility to accommodate 'contextual details of situations' (Mackay, 2020: 78). For instance, informed by the findings, the guidelines should represent decision-making that recognises the legitimacy of, and mediates the multiplicity of parties and their views that are entailed in child healthcare. They should clarify the ideal situation is where:

1. More than one carer is trained to tube-feed a child to alleviate fatigue.

2. Training recognises the clinical, practical, psychological, and social aspects of tube-feeding, including ways to manage stigma and isolation.

3. Different training modes are offered to accommodate different learning styles and preferences.

4. Clinicians and carers co-facilitate training given their respective areas of expertise and their different capacities to engage and train others.

5. Children who tube-feed are supported by a multidisciplinary team that convenes regularly with the child and their carer to understand each other's needs and preferences; familiarise with relevant guidelines, policies, and protocols, including those on grievance procedures; determine the terms of engagement, including the regularity and mode of meetings; establish and pursue shared goals; revisit these regularly; and revise these, as appropriate. 
6. Children, their carer, and clinicians have determined how conflicts should be managed - this might involve sourcing guidance from specialists not involved in the child's care and people with lived experience and/or enlisting consumer and/or carer advocates.

7. Children and carers are encouraged and supported to access peer support.

The findings also have implications for scholars. There is a need for scholarship that considers how children define and experience moral concerns; and how these impact health outcomes. Such scholarship would benefit from participatory methods to involve children and clarify their roles in relationships that optimise the shared pursuit of tube-feeding care (Bray et al., 2019).

\section{Conclusion}

This article extends knowledge about moral concerns in child healthcare. With reference to tubefeeding, it establishes the challenges that can emerge when different concerns intersect - specifically, the beliefs, feelings, and actions that can strengthen or challenge relationships and open, perhaps divergent, dialogue between those involved.

Furthermore, this article demonstrated how an ethic of care can meld the aforesaid concerns to foster the relationships required to pursue a shared goal - the health outcomes of the child and carer. This ethic of care was grounded in myriad interdependencies between clinicians, carers, and children; and taking time and care to make decisions about feeding care, so that crucial contextual features of feeding care could be considered.

This article highlights the need to enact an ethic of care around paediatric tube-feeding to strengthen clinician and carer relationships by openly considering divergent beliefs, acknowledging strong emotions, and addressing the challenges of normalising tube-feeding in ways that matter to families. By adopting an ethics of care, concerns can be fruitfully blended in shared decisionmaking to benefit clinician and carer relationships; individual autonomy; and the health of children and their carers.

\section{Acknowledgements}

The authors wish to thank Ms Claire Reilly for her assistance.

\section{Declaration of conflicting interests}

The author(s) declared no potential conflicts of interest with respect to the research, authorship, and/or publication of this article.

\section{Funding}

The author(s) disclosed receipt of the following financial support for the research, authorship, and/or publication of this article: This study was funded by the Western Sydney University School of Business and the University of Technology Sydney Centre for Carers Research.

\section{ORCID iDs}

Ann Dadich 荢https://orcid.org/0000-0001-5767-1794

Nick Hopwood 劳https://orcid.org/0000-0003-2149-5834 


\section{References}

Adams RC and Elias ER (2014) Nonoral feeding for children and youth with developmental or acquired disabilities. Pediatrics 134(6): e1745-e1762.

Almqvist-Tangen G, Arvidsson S, Alm B, et al. (2017) What makes parents act and react? Parental views and considerations relating to 'child health' during infancy. Journal of Child Health Care 21(4): 415-423.

Beauchamp TL and Childress JF (2001) Principles of Biomedical Ethics. New York, NY: Oxford University Press.

Blazin LJ, Terao MA, Spraker-Perlman H, et al. (2021) Never enough time: mixed methods study identifies drivers of temporal demand that contribute to burnout among physicians who care for pediatric hematologyoncology patients. JCO Oncology Practice 17(7): e958-e971.

Braun Vand Clarke V (2021) To saturate or not to saturate? Questioning data saturation as a useful concept for thematic analysis and sample-size rationales. Qualitative Research in Sport, Exercise and Health 13(2): 201-216.

Braun V, Clarke V, Terry G, et al. (2018) Thematic analysis. In: Liamputtong P (ed) Handbook of Research Methods in Health and Social Sciences. Singapore: Springer, 843-860.

Bray L, Horowicz E, Preston K, et al. (2019) Using participatory drama workshops to explore children's beliefs, understandings and experiences of coming to hospital for clinical procedures. Journal of Child Health Care. Epub ahead of print 22 October 2019. DOI: 10.1177/1367493519883087.

Brenner M, Kidston C, Hilliard C, et al. (2018) Children's complex care needs: a systematic concept analysis of multidisciplinary language. European Journal of Pediatrics 177(11): 1641-1652.

Camp-Spivey LJ, Logan A and Nichols M (2021) Theoretical and contextual considerations for selfmanagement strategies of children and adolescents with chronic diseases: an integrative re- view. Journal of Child Health Care: 1-20. Epub-Ahead-of-Print 29 April 2021. DOI: 10.1177/ 13674935211013697.

Carnevale FA and Manjavidze I (2016) Examining the complementarity of 'children's rights' and 'bioethics' moral frameworks in pediatric health care. Journal of Child Health Care 20(4): 437-445.

Conradi E (2018) Forgotten approaches to care: the human being as neighbour in the German-Jewish tradition of the nineteenth century. In: Krause F and Boldt J (eds) Care in Healthcare: Reflections on Theory and Practice. Cham: Palgrave Macmillan, 13-35.

Craig G and Higgs P (2012) Risk owners and risk managers: dealing with the complexity of feeding children with neurodevelopmental disability: negotiating and communicating health risk. Health, Risk \& Society 14(7-8): 627-637.

Craig GM and Scambler G (2006) Negotiating mothering against the odds: gastrostomy tube feeding, stigma, governmentality and disabled children. Social Science \& Medicine 62(5): 1115-1125.

Craig GM, Scambler G and Spitz L (2003) Why parents of children with neurodevelopmental disabilities requiring gastrostomy feeding need more support. Developmental Medicine and Child Neurology 45(3): 183-188.

De Panfilis L, Di Leo S, Peruselli C, et al. (2019) "I go into crisis when ...": ethics of care and moral dilemmas in palliative care. BMC Palliative Care 18(70): 70-78.

Dungan JA, Young L and Waytz A (2019) The power of moral concerns in predicting whistleblowing decisions. Journal of Experimental Social Psychology 85: 1-12.

DuPen MM, Van Tilburg MA, Langer SL, et al. (2016) Parental protectiveness mediates the association between parent-perceived child self-efficacy and health outcomes in pediatric functional abdominal pain disorder. Children (Basel, Switzerland) 3(3): 1-8.

Ferguson A (1991) Sexual Democracy: Women, Oppression, and Revolution. Boulder, CO: Westview Press. Freitag L (2018) Extreme Caregiving: The Moral Work of Raising Children with Special Needs. New York, NY: Oxford University Press.

Gilligan C (1982) A Different Voice: Psychological Theory and Women's Development. Cambridge, MA: Harvard University Press. 
Gilligan C (2014) Moral injury and the ethic of care: reframing the conversation about differences. Journal of Social Philosophy 45(1): 89-106.

Goday PS, Huh SY, Silverman A, et al. (2019) Pediatric feeding disorder - Consensus definition and conceptual framework. Journal of Pediatric Gastroenterology and Nutrition 68(1): 124-129.

Gramlich L, Hurt RT, Jin J, et al. (2018) Home enteral nutrition: towards a standard of care. Nutrients 10(8): $1-11$.

Harris HA, Ria-Searle B, Jansen E, et al. (2018) What's the fuss about? Parent presentations of fussy eating to a parenting support helpline. Public Health Nutrition 21(8): 1520-1528.

Harsh S (2011) Purposeful sampling in qualitative research synthesis. Qualitative Research Journal 11(2): $63-75$.

Held V (2006) The Ethics of Care. New York, NY: Oxford University Press.

Hopwood N, Elliot C, Moraby K, et al. (2020) Parenting children who are enterally fed: how families go from surviving to thriving. Child: Care, Health and Development 46(6): 741-748.

Houtzager BA, Möller EL, Maurice-Stam H, et al. (2015) Parental perceptions of child vulnerability in a community-based sample: association with chronic illness and health-related quality of life. Journal of Child Health Care 19(4): 454-465.

Krom H, van Zundert SMC, Otten M-AGM, et al. (2019) Prevalence and side effects of pediatric home tube feeding. Clinical Nutrition 38(1): 234-239.

Mackay K (2020) Feminism and feminist ethics. In: Hendricks C and Matthews G (eds) Introduction to Philosophy: Ethics. Montreal: Rebus Foundation, 64-74.

Mahant S, Cohen E, Nelson KE, et al. (2018) Decision-making around gastrostomy tube feeding in children with neurologic impairment: engaging effectively with families. Paediatrics \& Child Health 23(3): 209213.

Mahant S, Jovcevska V and Cohen E (2011) Decision-making around gastrostomy-feeding in children with neurologic disabilities. Pediatrics 127(6): e1471-e1481.

Mandal J, Ponnambath D and Parija S (2016) Utilitarian and deontological ethics in medicine. Tropical Parasitology 6(1): 5-7.

Memorial Sloan Kettering Cancer Center (2020) Tube feeding using the gravity method. Available at: https:// www.mskcc.org/cancer-care/patient-education/tube-feeding-using-gravity-method (accessed 5 April 2020).

Moreton KL (2019) Reflecting on 'Hannah's choice': using the ethics of care to justify child participation in end of life decision-making. Medical Law Review 28(1): 124-154.

NSW Health. (2016). Feeding Difficulties in Children - A Guide for Allied Health Professionals. Sydney, NSW: NSW Health.

Park J, Wood J, Bondi C, et al. (2016) Anxiety evokes hypofrontality and disrupts rule-relevant encoding by dorsomedial prefrontal cortex neurons. Journal of Neuroscience 36(11): 3322-3335.

Pearce CB and Duncan HD (2002) Enteral feeding. Nasogastric, nasojejunal, percutaneous endoscopic gastrostomy, or jejunostomy: its indications and limitations. Postgraduate Medical Journal 78: 198-204.

Philosophy Lander (n.d.) What is a moral issue? Available at: https://philosophy.lander.edu/ethics/issue.html (accessed 4 March).

Richards S (2017) Enteral feeding and medication administration. Available at: https://www.rch.org.au/ rchcpg/hospital_clinical_guideline_index/Enteral_feeding_and_medication_administration/_ (accessed on 4 January).

Sanzone LA, Lee JY, Divaris K, et al. (2013) A cross sectional study examining social desirability bias in caregiver reporting of children's oral health behaviors. BMC Oral Health 13(24): 24-29.

Serjeant S and Tighe B (2021) A meta-synthesis exploring caregiver experiences of home enteral tube feeding. Journal of Human Nutrition and Dietetics. Epub-ahead-of-print. DOI: 10.1111/jhn.12913.

Sharp WG, Volkert VM, Scahill L, et al. (2018) A systematic review and meta-analysis of intensive multidisciplinary intervention for pediatric feeding disorders: how standard is the standard of care? Appetite 181: 116-124.

Silverman AH, Erato G and Goday P (2021) The relationship between chronic paediatric feeding disorders and caregiver stress. Journal of Child Health Care 25(1): 69-80. 
Tang D, Parker EK, Faruquie SS, et al. (2018) Evaluation of home enteral nutrition services at public hospitals in New South Wales, Australia. Nutrition \& Dietetics 76(1): 6-13.

Tong R and Williams N (2018) Feminist ethics. In: Zalta EN (ed) The Stanford Encyclopedia of Philosophy. Winter edition. Stanford, CA: Metaphysics Research Lab, Center for the Study of Language and Information, Stanford University.

Yang HR (2017) How to approach feeding difficulties in young children. Korean Journal of Pediatrics 60(12): 379-384. DOI: 10.3345/kjp.2017.60.12.379.

Zimmerman E and Rosner A (2018) Feeding swallowing difficulties in the first three years of life: a preterm and full-term infant comparison. Journal of Neonatal Nursing 24(6): 331-335. 